\title{
Outcomes of National Community Organization Cardiovascular Prevention Programs for High-Risk Women
}

\author{
Amparo C. Villablanca - Shavon Arline - Jacqui Lewis • \\ Sekar Raju • Susan Sanders • Shannon Carrow
}

Received: 12 February 2009 / Accepted: 4 June 2009 /Published online: 30 June 2009

(C) The Author(s) 2009. This article is published with open access at Springerlink.com

\begin{abstract}
The purpose of this study was to reduce cardiovascular disease (CVD) risk in women by implementing a cardiovascular prevention health promotion program in faith- and community-based sites. The primary outcomes were reducing obesity and increasing physical activity. A longitudinal cohort of high-risk (age $>40$, ethnic minority) women $(n=1,052)$ was enrolled at 32 sites across the USA. The pre- or post-educational intervention consisted of eight biweekly counseling sessions conducted over 4 months each addressing one of six of the major CVD risk factors (smoking, diabetes, hypertension, cholesterol, obe-
\end{abstract}

\footnotetext{
A. C. Villablanca $(\bowtie)$

Cardiovascular Medicine,

University of California, Davis,

One Shields Ave., TB 172,

Davis, CA 95616-8636, USA

e-mail: avillablanca@ucdavis.edu

S. Arline

Black Women's Health Imperative,

Washington, D.C., USA

J. Lewis

Association of Black Cardiologists,

Atlanta, GA, USA

S. Raju

Iowa State University,

Ames, IA, USA

S. Sanders

Office on Women's Health,

Department of Health and Human Services,

Washington, D.C., USA

S. Carrow

Research Center for Stroke \& Heart Disease,

The Jacobs Neurological Institute,

Buffalo, NY, USA
}

sity, and physical inactivity) as well as signs and symptoms of a heart attack and stroke; plus 4-6 maintenance sessions over three additional months. A multifaceted approach delivered by lay and medically trained personnel involving medical screenings, health behavior counseling, risk behavior modification, and stage of change were determined at baseline and end of counseling or maintenance. Following list-wise deletion, data were analyzed on 423 women who completed all follow-up time-points. Overall, significant improvement was attained in most of 28 secondary outcomes but not in the primary outcomes. Knowledge and awareness of heart disease as the leading killer or women, all of the signs and symptoms of a heart attack, calling 911, and CVD risk factors increased significantly $(p<0.05)$ by $8.8 \%, 13.6 \%, 5.8 \%$, and $10 \%$, respectively. There was a $10 \%(p<0.05)$ increase in participants attaining control for hypertension (blood pressure $<140 / 90$ ) coupled with a significant reduction in mean blood pressure in the entire cohort. Knowledge of effective CVD risk modification strategies for all CVD risk factors increased significantly $(p<0.05)$, except for obesity. In addition, there were significant $(p<0.05)$ increases in forward movement in stage of change for each CVD risk factor (range $+10 \%$ to $+39 \%$ ). Thus, a heart disease prevention intervention built around a model of community engagement, advocacy, self-efficacy, resource knowledge, and health promotion in faith- and community-based organizations is successful at improving cardiovascular knowledge and awareness outcomes in high-risk women. Limitations of our study include the high dropout rate, significant time demands on site coordinators, limited resources for program implementation, lack of morbidity and mortality endpoints, and failure to attain the primary outcomes of weight loss and physical activity. Future studies should not only assess the effect of community education interventions on lifestyle change and 
knowledge and awareness of participants but should also address program duration, cost, and resources required to attain improved outcomes.

Keywords Heart Disease · Women · Minority · Prevention · Community-Based · Faith-Based Organization ·

Education and Awareness

\section{Introduction}

Cardiovascular disease (CVD), including heart disease and stroke, is the leading cause of death for women in the USA [1]. Compared to men, women have higher CVD mortality, higher morbidity following a heart attack or stroke, lower awareness of CVD, and a higher prevalence of most major risk factors for CVD. Since 1984, the number of CVD deaths for females has exceeded those for males in the USA [2]. In 2002, about 60,000 more US women died of CVD than men [2], and $38 \%$ of women die within 1 year of having a heart attack compared to $25 \%$ of men who have heart attacks [1]. Yet, heart disease is largely preventable.

Some experts speculate that the difference in CVD outcomes and risk factor prevalence between women and men may be due, in part, to a lack of awareness among women and their physicians of the risks for CVD in women $[3,4]$. A 2003 national survey conducted by the American Heart Association found that $35 \%$ of women cite breast cancer as their greatest health threat while only $13 \%$ of women believe that their greatest health threat is heart disease [5]. However, more women die of heart disease than of all cancers combined. Furthermore, although awareness over time has improved slightly, the majority of women fail to identify the risk factors for heart disease, such as high blood pressure and high cholesterol [5]. Yet, more women than men in the US have the five major risk factors for CVD: high blood pressure, high cholesterol, type 2 diabetes, physical inactivity, and obesity [2]. Thus, a key to prevention in women is increased awareness of risk.

The issues attributing to women's increased CVD risk pertain to factors that relate to more than knowledge and awareness of threat. Health professionals and women need education on heart disease risk and its symptomatology [4-7]. The most common heart attack symptoms in women differ from those in men, and women are more likely than men to experience "atypical" symptoms [8]. Ethnic minority women have greater lack of heart disease symptom awareness and of the risk factors that predominate in ethnic or racial minority groups than white women $[4,9]$; therefore, greater education is needed in this area as well.

The need to improve preventive interventions and messaging is even greater for women over the age of 40 , particularly those in underrepresented groups [10]. A woman's risk of CVD starts to rise between the ages of 40 and 60; thus, behavioral modification programs that target women aged 40 years and older have the potential to prevent CVD and its risk factors including obesity, hypertension, high LDL cholesterol, and type 2 diabetes that often develop around the ages of 40 to 60 [10]. Thus, women aged $>40$ are a high-risk group. In addition, because African-American women have the highest ageadjusted heart disease and stroke death rates of any female race or ethnicity group in the USA [10], a higher prevalence of many major risk factors for CVD [2, 11, 12], and lower awareness of CVD threat, this group of women stand to gain significantly from modalities designed for prevention and risk reduction. Health disparities in racial or ethnic minority groups have inspired researchers and health practitioners to address the disproportionate high morbidity and mortality rates from CVD in these groups.

Targeted CVD behavioral modification interventions, including those in community settings and those incorporating counseling efforts, have been successful in modifying cardiovascular risk behaviors in women [13-17]. However, risk behavior modification that translates knowledge into practice is pivotal to achieving improved health outcomes. Particularly effective strategies for modifying CVD risk behaviors of women include attention to stage-ofchange, physical activity, process variables, community participation or social networks, empowerment, and communitywide counseling program [15, 18-27]. The Centers for Disease Control and Prevention's Racial and Ethnic Approaches to Community Health (www.cdc.gov/reach) aims to address the Healthy People 2010 goal of eliminating health disparities among segments of the population, utilizing a model with demonstrated effectiveness for health promotion in a number of settings [28].

With this foundational evidence, the purpose of the present CVD prevention study was to design and implement a pre/post educational intervention with the primary goal of reducing CVD risk in high-risk women in community- and/or faith-based sites across the USA through a multifaceted approach involving medical screenings, health behavior counseling and risk behavior modification. The heart disease prevention activities were built around a model of community engagement, advocacy, selfefficacy, resource knowledge, and participant education. We hypothesized that a cardiovascular disease prevention program targeting high-risk women and implemented in local community networks would enhance knowledge and awareness of heart disease and its attendant risk factors, reduce cardiovascular risk, change attitudes, promote physical activity, and help women establish or maintain a healthy weight. 


\section{Methods}

\section{Performance Sites}

This study was sponsored by the US Department of Human Health Services, Office on Women's Health (DHHS-OWH) through a competitive award mechanism. Four lead sites were selected. Each was either a national faith-based or national community organization having a network of at least 10 sites across the USA with large populations of high-risk women (defined as racial and ethnic minority women, aged 40 years and older) or partnered with a national faith-based or national community organization having such a network. Two of the lead sites were academic medical centers and two were nonacademic institutions. A brief description of each lead site is provided below. A listing of the 32 community- and faith-based affiliated partner sites is summarized in Table 1.
The Association of Black Cardiologists The Association of Black Cardiologists (ABC), a nonprofit organization founded in 1974, conducts continuing medical education for physicians, community-based interventions for patients, screenings for cardiovascular disease, and advocates for health policy to effect improvement in community wellbeing. For this study, ABC worked in partnership with the United Church of Jesus Christ.

The Black Women's Health Imperative The Black Women's Health Imperative (The Imperative), formerly the National Black Women's Health Project, a national nonprofit 501(c) (3) organization founded in 1983, advocates for women's health and leadership development and is devoted solely to ensuring optimum health of Black women and girls. Consistent with a self-help or care approach, the Imperative has a network of 40 affiliated organizations and communitybased field offices across the country for actively engaging

Table 1 Community- and faith-based study sites

\begin{tabular}{|c|c|c|c|}
\hline \multicolumn{4}{|l|}{ Study lead sites } \\
\hline $\mathrm{ABC}$ & The Imperative & RCSHD & UC Davis \\
\hline \multicolumn{4}{|l|}{ Participating partner community and faith-based sites } \\
\hline $\begin{array}{l}\text { Baltimore, MD: Transformation } \\
\text { Ministries of UCJC }\end{array}$ & $\begin{array}{l}\text { Turner Chapel AME Church; } \\
\text { Marietta, GA } \\
\text { Sigma Mu Zeta-(Zeta Phi Beta); } \\
\text { Marietta, GA }\end{array}$ & $\begin{array}{l}\text { Seattle, WA: St. Andrew Kim } \\
\text { Church }\end{array}$ & Eastern Shore, NY \\
\hline $\begin{array}{l}\text { Yemassee, SC: Family Worship Center } \\
\text { (Apostolic) }\end{array}$ & $\begin{array}{l}\text { Center for Black Women's Wellness; } \\
\text { Atlanta, GA } \\
\text { Atlanta Chapter Mocha Mom; } \\
\text { Atlanta, GA }\end{array}$ & $\begin{array}{l}\text { Lodge Grass, MT: Our Lady } \\
\text { of Loretto Church }\end{array}$ & Fresno, CA \\
\hline $\begin{array}{l}\text { Lakeland, FL: Greater Faith Christian } \\
\text { Center, 1st Pentecostal Apostolic Church, Inc }\end{array}$ & $\begin{array}{l}\text { New Covenant AME Church; } \\
\text { Charlotte, NC }\end{array}$ & $\begin{array}{l}\text { Carthage, MO: Grace Episcopal } \\
\text { Church }\end{array}$ & Phoenix, AZ \\
\hline $\begin{array}{l}\text { Yonkers, NY: United Church } \\
\text { of Jesus Christ }\end{array}$ & $\begin{array}{l}\text { Delta Zeta (Zeta Phi Beta); } \\
\text { Charlotte, NC }\end{array}$ & $\begin{array}{l}\text { Detroit, MI: Most Holy } \\
\text { Redeemer }\end{array}$ & $\begin{array}{l}\text { Prince Georges } \\
\text { County, MD }\end{array}$ \\
\hline $\begin{array}{l}\text { Spring Lake, NC: The Soul Harvest Apostolic } \\
\text { Church }\end{array}$ & $\begin{array}{l}\text { Chicago Chapter, Mocha Moms; } \\
\text { Chicago, IL } \\
\text { Tau Xi Zeta (Zeta Phi Beta); } \\
\text { Chicago, IL }\end{array}$ & $\begin{array}{l}\text { St. Louis, MO: Centennial } \\
\text { Christian Church }\end{array}$ & Sacramento, CA \\
\hline $\begin{array}{l}\text { Decatur, GA: Kingdom Building } \\
\text { Worship Ministries }\end{array}$ & Mt. Calvary AME; Towson, MD & $\begin{array}{l}\text { Buffalo, NY: Mt. Olive Baptist } \\
\text { Church }\end{array}$ & Selma, AL \\
\hline Orange, NJ: 1st United Tabernacle Church & $\begin{array}{l}\text { Lambda Pi Zeta (Zeta Phi Beta); } \\
\text { Carson, CA } \\
\text { Auxiliary: Carson Zeta Amicae } \\
\text { (Zeta Phi Beta); Carson, CA } \\
\text { Grant AME Church; Los Angeles, CA }\end{array}$ & $\begin{array}{l}\text { Atlanta, GA: Atlanta } \\
\text { Intercultural Ministries, Inc. }\end{array}$ & Shelby County, TN \\
\hline Randallstown, MD: Set the Captives Free & AME Union Church; Philadelphia, PA & $\begin{array}{l}\text { Ypsilanti, MI: Brown Chapel } \\
\text { A.M.E. Church }\end{array}$ & Windy City, IL \\
\hline Columbia, SC: Rehoboth United Apostolic & Philadelphia Chapter, Mocha Moms & $\begin{array}{l}\text { Cleveland, OH: La Sagrada } \\
\text { Familia }\end{array}$ & - \\
\hline Gwynn Oak, MD: Mount Olive Holy Evangelical & Beta Delta Zeta; Philadelphia, PA & - & - \\
\hline
\end{tabular}

N/A site dropped out or declined to participate, UCJC United Churches of Jesus Christ, ABC Association of Black Cardiologists, The Imperative Black Women's Health Imperative, RCSHD Research Center for Stroke and Heart Disease, UC Davis University of California, Davis Women's Cardiovascular Medicine Program, $A M E$ African Methodist Episcopal Church Connectional Health Commission, $C B W W$ Center for Black Women's Wellness; MM Mocha Moms, Inc.; ZETA Zeta Phi Beta Sorority, Inc. 
Black women in their personal health and wellness. For this study, the Imperative established partnerships with the African Methodist Episcopal Connectional Health Commission, Center for Black Women's Wellness, Mocha Moms, Inc., and Zeta Phi Beta Sorority, Inc.

Research Center for Stroke \& Heart Disease The Research Center for Stroke \& Heart Disease is a 501(c)(3) organization founded in 1997, a division of the Jacobs Neurological Institute at the State University of New York at Buffalo. The entirely grant funded organization was established to raise awareness of and prevent stroke and heart disease in communities. The Center designs, implements, and evaluates studies to educate individuals and motivate them to adopt practices effective in reducing risk factors. The Center employs several fulltime and part-time staff and contractors with expertise in health care management, epidemiology, communications, and computer programming. Staff engage in grant writing; study or project design, implementation, and evaluation; health research and epidemiological surveillance/ profiling; data collection, management, and analysis; and disseminating results. The Center is the go-to organization for regional and statewide stroke and heart disease death and prevalence statistics and associated risk factors. For this study, the RCSHD partnered with a number of faith-based sites around the country selected on the basis of their CVD risk and ethnic and geographic diversity.

\section{University of California, Davis Women's Cardiovascular} Medicine Program The Women's Cardiovascular Medicine Program at the University of California, Davis was established in 1994 as one of the first women's heart programs in the country. The program is under the dual umbrella of the UC Davis Health System's Heart Center and the Department of Internal Medicine in the School of Medicine. The comprehensive and interdisciplinary program focuses on providing state-of-the-art cardiovascular health care and prevention for women through advocacy, clinical care, education, and community engagement. The program also fosters and conducts research that addresses women's heart health issues and gender differences in heart disease utilizing basic science, translational, and epidemiological approaches. For this study, the University of California, Davis partnered with The Links, Inc., a national nonprofit community organization of professional African-American women involved in volunteer community work to favorably influence life course in African-American communities.

\section{Participants and Recruitment}

This was a longitudinal pre- or post-educational health promotion intervention study conducted between September 2006 and May 2008. Participants were recruited as a cohort between January 2007 and June 2007 from the participating faith-based groups and national community organization sites. Each lead site selected a minority population group of women based on the organization's history of prior collaboration, direct programmatic delivery with the selected organization or group, or national needs assessment focused on CVD risk, ethnic diversity, and geographic dispersion. Recruitment strategies included program and church announcements and advertisements, pastor speaking guides, flyers, organization chapter meetings, website announcements, word of mouth, and encouragement from other members. The study site leaders used their congregations, local social ties, and networks to recruit and retain women in the study. Study women were a part of the communities the organizations served or were affiliated with the local chapter, church, or community organization. The study population included high-risk women (racial and ethnic minority women aged 40 years and older); however, all high-risk women were eligible to participate in the program regardless of race, religion, or age. Participants were given incentives during the intervention to encourage continued participation (e.g., pedometers, heart healthy cookbooks, red dress pins, etc.). The Human Subjects Review Panels of each of the lead study site organization or institutions approved this study, and all participants provided informed consent.

\section{Program Implementation and Study Design}

Each lead site implemented one program in partnership with up to ten faith- and/or community-based partner sites across the USA. There were four phases to program implementation: Phase I-Program Planning, Development, and Recruitment; Phase II (4 months) - Counseling Sessions; Phase III (3 months)_-Maintenance Sessions; and Phase IV_-Program Evaluation/Write-Up. The total study performance period was 18 months. The total period of intervention was 7 months. Each phase of implementation is briefly summarized below.

Phase I-Program Planning, Development and Recruitment An orientation meeting was held in Washington, DC with the PIs of each lead site, senior-level project managers, and the Office on Women's Health project manager to clarify tasks and requirements, answer questions, and ensure uniform implementation of the program. Lead sites worked collectively on a standard survey assessment instrument used to collect data from all participants. The survey instrument assessed demographic, clinical parameter, health history, health behavior, and knowledge and awareness variables. Each lead site formed a multidisciplinary planning committee for consultation in designing the educational seminars, ensuring cultural appropriateness, and to assist with 
identifying site leaders (typically a faith-based or community leader or a health professional affiliated with the individual sites). Site leaders were trained on the intervention via a required 1-day training course, developed and administered by the lead site. Site leaders were charged with recruiting participants from their organizations, churches, and local communities, enrolling participants and administering informed consent, and encouraging participant retention in the program. The program was delivered at each site by the site leaders and incorporated qualified cardiologists, endocrinologists, nurses, dietitians, physical exercise, and other health professionals in the development and/or implementation of the curriculum and small group discussions.

The lead sites assisted site leaders in compiling a local directory of cardiovascular resources (cardiologists, dieticians, diabetes experts, weight loss and exercise programs, public health screening, and diagnosis information) available in the community of each site, including healthcare alternatives for the uninsured and underinsured women. Each lead site prepared a site leader manual and toolkit to implement the cardiovascular program in their community. Lead sites established a website or enhanced an existing organization's website to provide cardiovascular support and information online unique to their geographical location and population group. Websites were linked to the DHHS/OWH "For Your Heart" website (http://www.4women.gov/hhs) and to the National Heart Lung and Blood Institute's "Heart Truth" campaign website (http://www.nhlbi.nih.gov/health/hearttruth/). Additional materials used to promote the program, provide additional cardiovascular disease information, and highlight progress made by individual sites and participants included a print and/or web-based newsletter distributed to all partnering sites and participants.

Phase II-Counseling Sessions Each faith- or communitybased site conducted eight biweekly group counseling sessions over a period of 4 months. The sessions lasted 90-120 min each and were located at the faith- or community-based site or at other appropriate clinical facilities in the community. Each session addressed one of the six major risk factors for CVD (smoking, diabetes, hypertension, cholesterol, obesity, and physical inactivity), ways to modify risk, and the benefits associated with risk modification. In addition, stress prevention and the signs or symptoms of heart attack and stroke in women were addressed during at least one of the eight group counseling sessions. Sessions included interactive and clinical lectures, health demonstrations, video presentations, personal testimonies, and other heart healthy activities. Additional activities during counseling sessions included pre- and post-knowledge tests, medical screenings, and low to moderate physical activity (dancing, walking, chair exercises, yoga, or aerobics). Participants were encouraged and organized to also meet in groups at least once a week to engage in some form of moderate intensity physical activity. Each counseling session also included small group discussion focused on encouraging participants to incorporate weight control strategies and physical activity into their daily lives. Participants were encouraged to use selfmonitoring tools (logs, journaling, health passports) and establish lifestyle change goals. Participant attendance at each session was encouraged by the site leader, group members, and/or a buddy system and varied from $100 \%$ to approximately $50-75 \%$ depending on the session and time of year.

Before the first counseling session (baseline), participants were screened for all six major CVD risk factors and assessed their CVD risk profile and stage of change via a pretest with a self- or interviewer-administered survey. During the last counseling session, participants performed the same screenings and assessments as at baseline using a post-test identical to the baseline survey. Screenings included height, weight, body mass index (BMI), systolic and diastolic blood pressure, and fasting blood tests for total cholesterol and blood glucose. Community partners (city and county health departments, community health clinics, recharge labs) assisted each site with the screenings.

Phase III-Maintenance Sessions The maintenance sessions directly followed the group counseling sessions and lasted for an additional 3 months. The purpose of maintenance was to provide program participants additional time in counseling, motivate participants to meet personal goals established at the onset of the program, and help "maintain" healthy lifestyle practices achieved during the counseling sessions. Site leaders and participants decided themselves on the number, frequency, and format of the maintenance sessions which included any or all of the following activities: additional group counseling seminars, screenings, testimonials, personal counseling, field trips (fitness centers, grocery stores, restaurants to practice selecting healthy foods), etc. Each session typically lasted 90-120 min and included a physical activity and a small group discussion component. During maintenance participants were encouraged to continue to organize and to meet in smaller groups at least once a week to engage in some form of physical activity. Participant attendance was encouraged as for counseling sessions and varied from $100 \%$ to approximately $50-100 \%$ depending on the time of year.

At the end of the maintenance sessions, participants were screened again for all six major CVD risk factors and selfassessed their own personal CVD risk profile and stage of change. Participants performed the same screenings and 
assessments as at end of counseling using a post-test identical to the end of counseling and baseline survey.

Phase IV-Program Evaluation Data were also obtained from self-monitoring materials and from feedback and evaluation forms.

\section{Outcome Variables and Metrics}

A total of 28 outcomes or sub-outcomes were evaluated. The primary outcomes (reducing obesity and increasing physical activity) and major secondary outcomes for the study are summarized in Table 2. In selecting program outcomes, emphasis was placed on aligning objectives and targets with those of Healthy People 2010 (http://www. health.gov/healthypeople). Knowledge and awareness about heart disease and its symptoms, knowledge of cardiovascular health status and cardiovascular risk factors, knowledge of effective interventions for risk factor modification, and clinical parameters were all assessed. Each lead site designed a local database for the purpose of collecting and entering participant data from its affiliated

Table 2 Primary and secondary outcomes assessed in response to the cardiovascular disease prevention intervention

Primary outcome measures

Decrease the proportion of women who are obese $\left(\mathrm{BMI}>=30 \mathrm{~kg} / \mathrm{m}^{2}\right.$ )

Increase the proportion of women who engage regularly (at least $30 \mathrm{~min} /$ day) in moderate physical activity (outside of program sessions)

Secondary outcome measures

Decrease the proportion of women who smoke cigarettes

Increase the proportion of women with diabetes at baseline whose diabetes is under control (FBS $<=125 \mathrm{mg} / \mathrm{dl}$ )

Increase the proportion of women with high blood pressure at baseline whose blood pressure is under control ( $\mathrm{SBP}<=140 \mathrm{mmHg}$, $\mathrm{DBP}<=90 \mathrm{mmHg}) ;(\mathrm{SBP}<=120 \mathrm{mmHg}, \mathrm{DBP}<=80 \mathrm{mmHg})$

Decrease the proportion of women with high total blood cholesterol $(>240 \mathrm{mmHg} ;>200 \mathrm{mmHg}$ )

Increase the proportion of women who are aware that heart disease is the \#1 killer of women

Increase the proportion of women who are aware of the early warning symptoms and signs of a heart attack and the importance of accessing rapid emergency care by calling 911

Increase the proportion of women who know all of the major risk factors for CVD (overweight, physical inactivity, smoking, diabetes, blood pressure, cholesterol)

Increase the proportion of women who know how to modify the major risk factors for CVD (overweight, physical inactivity, smoking, diabetes, blood pressure, cholesterol)

For each CVD clinical risk factor (overweight, physical inactivity, smoking, diabetes, blood pressure, cholesterol), move $50 \%$ of women forward at least one Stage of Change sites. Data confidentiality was kept through the use of unique numeric identifiers.

Data Coordinating Center, Data Management, and Data Analysis

The RCSHD performed all data and statistical analyses for this study on data collected at each of the study time points (baseline, end of counseling session, and end of maintenance) using a predefined data dictionary. Data were analyzed using SPSS (version15.0 for Windows; SPSS Inc., Chicago, IL). The program evaluation was established to demonstrate, at minimum, the primary and secondary outcome measures and the overall effectiveness of the program. For all analyses, a list-wise deletion was performed and only participants with data at all three data collection periods were included in the longitudinal analyses $(n=423)$. The number of women, for whom there was a complete dataset, the number for whom there was not, and the percentage of women with incomplete data, is provided in Table 5 .

For normally distributed variables, arithmetic means and SDs were calculated. For categorical variables, frequencies, and proportions were calculated. The three time points were treated as a within-participants factor (effect over time). Survey answers were recoded to reflect presence or absence of knowledge/health state/behavior (e.g., 0 - does not know all symptoms for heart attack, 1 -knows all symptoms for heart attack). Frequency tables were generated for demographic, clinical, and knowledge variables as well as subgroups (age, race or ethnicity, education, site, etc.), and the proportion of participants in each knowledge, health state, or behavior was calculated. Difference in proportions across time were calculated for end of counseling and baseline, end of maintenance and baseline, end of maintenance, and end of counseling. Due to the repeated design of the study, difference scores were subjected to a two-tailed paired $t$ test to assess for significant differences from zero. For stages of change, differences in proportion across time were directly calculated. For each participant, forward movement was coded as +1 and lack of forward movement was coded as 0 . Coding reflected a count of the number of participants with forward movement between two study time periods. For each time period, the proportion of participants was calculated and analysis performed by assessing "differences in proportions" for a health behavior (e.g., increase in the proportion of women moving forward one or more stages of change for a health behavior). For interval scaled questions, when participant answers were provided on Likert scales, the mean values were subjected to repeated measures ANOVA. The Bonferroni correction was used for multiple comparisons. All statistical significance tests were at $\alpha=0.05$ level. 


\section{Results}

Participant Flow and Characteristics

One thousand, one hundred twenty-six women were recruited for the study. Figure 1 summarizes the flow of participants from the time of enrollment through study completion at 7 months. One thousand, fifty-two women consented to take part and enrolled in the study. Table 3 shows the demographics and characteristics of all participants at baseline. Over half of the cohort (51.4\%) was 40 60 years of age, a large proportion was Black (72.7\%), most were college graduates with health insurance, and the rest had a yearly income of over $\$ 40,000$. The cardiovascular risk profile of the study cohort is shown in Table 4. Nearly half of women were hypertensive (42\%) and on antihyper- tensive medications (41\%); yet, $34 \%$ reported poor blood pressure control (systolic blood pressure (SBP) $\geq 140 \mathrm{mmHg}$ or diastolic blood pressure (DBP) $\geq 90 \mathrm{mmHg}$ ). Over $38 \%$ of women were obese (BMI $>30 \mathrm{~kg} / \mathrm{m}^{2}$ ), and the mean BMI for the entire cohort was 32.2. In addition, nearly a third (30.6\%) were fairly sedentary (self reported physical activity $\leq 2$ days/ week), and $40.5 \%$ reported a family history of heart disease.

Effect of the Intervention on Knowledge and Awareness of Heart Disease, Symptoms, and Taking Action

We assessed the participant's knowledge and awareness for the following five variables: heart disease as the leading killer of women; all symptoms of a heart attack (myocardial infarction; MI); calling 911; all symptoms for MI+ calling 911; and all CVD risk factors. As shown in Fig. 2, baseline
Fig. 1 Flow of participants from recruitment to completion of final follow-up assessment. Flow diagram for participant recruitment, enrollment, participation in the group Counseling and Maintenance sessions, and dropout for all four national study sites

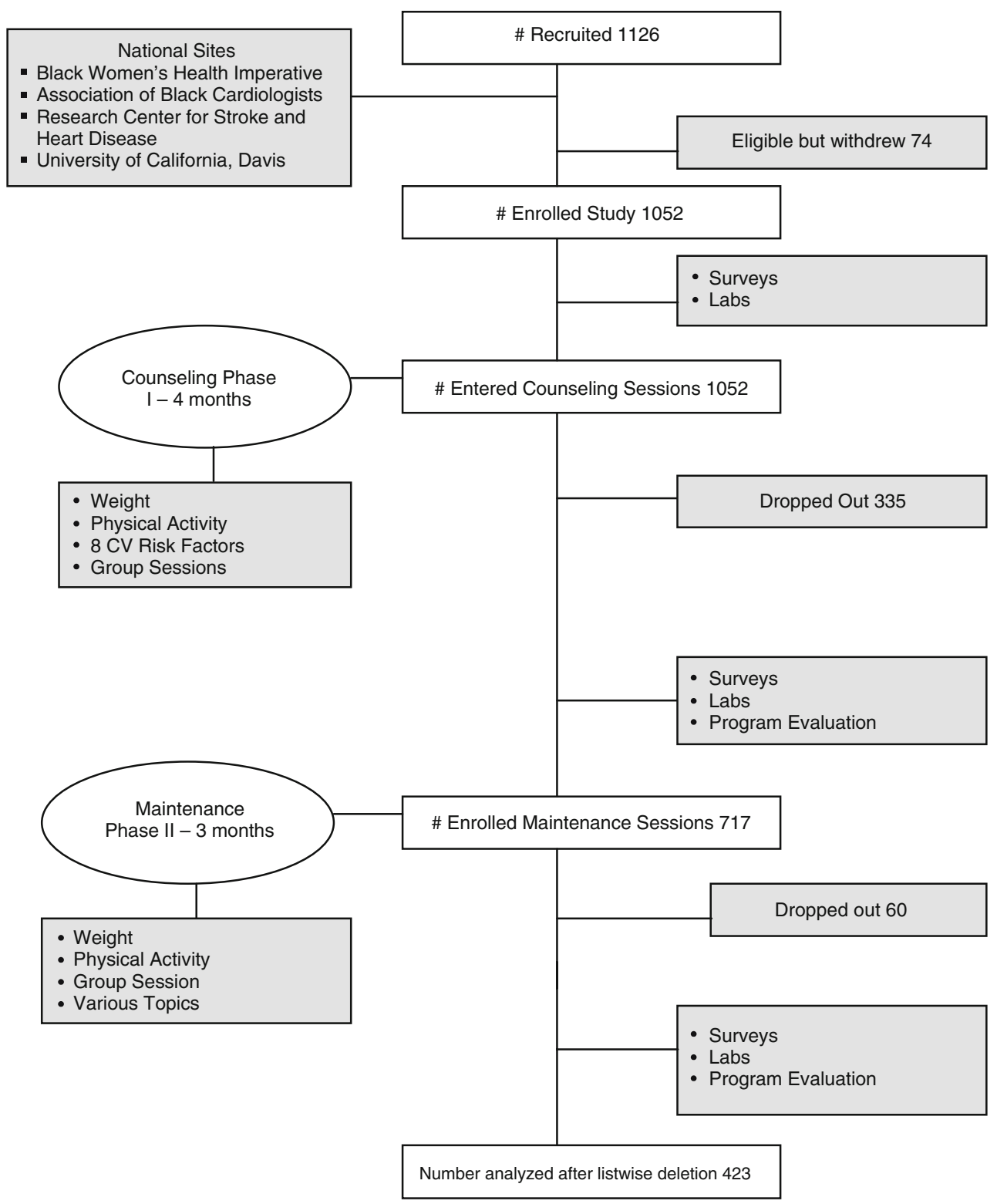


(B) knowledge and awareness was lowest for two of the five outcomes (all symptoms of MI, and all symptoms of MI + calling 911 (9.1\% and 9.8\%, respectively), and highest for the three remaining outcomes. There were significant $(p<0.05)$ gains in knowledge for all outcomes at the end of the counseling sessions (plus 8.8\%, 13.6\%, 5.8\%, 12.4\%, and $10 \%$ ) for knowledge of heart disease as the leading killer of women, all symptoms of a heart attack, calling 911, all symptoms for heart attack + calling 911, and all CVD risk factors, respectively (Fig. 2). The gains persisted into the end of maintenance for all outcomes. However, during maintenance, knowledge and awareness increased further and significantly $(p<0.05)$ for the three of the knowledge and awareness outcomes: heart disease as the leading killer, all symptoms of MI, and all symptoms of MI+ calling 911 by an additional $1.5 \%, 7.6 \%$, and $8.3 \%$, respectively (Table 5).

Table 3 Demographics of the study population at baseline

\begin{tabular}{|c|c|c|c|c|c|}
\hline \multirow[t]{2}{*}{ Characteristic } & \multicolumn{5}{|l|}{ Lead study site } \\
\hline & Total cohort, $\%$ enrollees & $\mathrm{ABC}$ & The Imperative & RCSHD & UC Davis \\
\hline Demographics, no. & $(n=1,052)$ & $254(24 \%)$ & $226(21.5 \%)$ & $246(23.4 \%)$ & $326(29.9 \%)$ \\
\hline \multicolumn{6}{|l|}{ Age, years } \\
\hline$<40$ & 13.1 & 22.4 & 19.9 & 12.2 & 8.6 \\
\hline $40-60$ & 51.4 & 42.4 & 54.4 & 60.2 & 50.5 \\
\hline$>60$ & 25.5 & 18.4 & 19.9 & 28.3 & 33.6 \\
\hline \multicolumn{6}{|l|}{ Race } \\
\hline Caucasian (non-Hispanic) & 3.8 & 0.3 & 0.0 & 15.2 & 0.3 \\
\hline Black (non-Hispanic) & 72.7 & 75.7 & 90.7 & 30.9 & 92.1 \\
\hline Asian/Pacific Islander & 1.9 & 0.3 & 0.0 & 7.8 & 0.0 \\
\hline American Indians/Alaska natives & 2.7 & 1.3 & 0.4 & 9.3 & 0.0 \\
\hline Other & 6.9 & 0.7 & 0.4 & 26.8 & 0.0 \\
\hline Unknown/Missing & 11.6 & 21.4 & 8.0 & 10.0 & 6.4 \\
\hline \multicolumn{6}{|l|}{ Ethnicity } \\
\hline Hispanic & 14.7 & 4.3 & 3.9 & 46.4 & 1.0 \\
\hline Non-Hispanic & 84.0 & 91.4 & 94.4 & 53.2 & 96.9 \\
\hline \multicolumn{6}{|l|}{ Education } \\
\hline Some high school or less & 8.9 & 8.2 & 1.8 & 21.6 & 4.0 \\
\hline High school graduate & 10.5 & 11.8 & 8.3 & 16.7 & 4.9 \\
\hline Some college, vocational, or technical school & 23.2 & 28.6 & 24.8 & 22.7 & 17.4 \\
\hline College graduate & 21.1 & 15.8 & 26.1 & 15.6 & 27.0 \\
\hline Post-graduate & 22.2 & 9.9 & 28.3 & 11.5 & 38.2 \\
\hline Unknown/missing & 13.8 & 25.0 & 9.73 & 10.8 & 7.3 \\
\hline \multicolumn{6}{|l|}{ Health insurance status } \\
\hline Medicaid or state & 6.2 & 7.6 & 4.0 & 8.9 & 4.3 \\
\hline Medicare & 14.7 & 14.1 & 11.1 & 16.7 & 15.9 \\
\hline HMO or other commercial & 49.0 & 36.2 & 62.0 & 33.5 & 64.8 \\
\hline Disability & 1.6 & 2.3 & 1.8 & 1.1 & 1.2 \\
\hline Private pay & 9.2 & 8.2 & 7.1 & 8.6 & 12.2 \\
\hline None & 12.4 & 12.2 & 10.2 & 26.8 & 2.5 \\
\hline Other & 6.7 & 4.9 & 7.1 & 9.7 & 5.5 \\
\hline Unknown/missing & 1.2 & 2.6 & 0.4 & 1.5 & 0.0 \\
\hline \multicolumn{6}{|l|}{ Socioeconomic status (income/year) } \\
\hline Up to $\$ 19,999$ & 9.9 & 10.2 & 7.5 & 20.8 & 2.5 \\
\hline$\$ 20,000-39,999$ & 16.1 & 18.8 & 16.4 & 20.8 & 9.5 \\
\hline$\$ 40,000-74,999$ & 21.7 & 18.8 & 25.7 & 17.1 & 25.4 \\
\hline$\geq \$ 75,000$ & 21.7 & 10.5 & 27.9 & 6.7 & 40.1 \\
\hline Unknown/missing & 21.9 & 34.9 & 13.3 & 23.4 & 14.4 \\
\hline
\end{tabular}


Table 4 Baseline cardiovascular risk profile of the study population

\begin{tabular}{|c|c|}
\hline Characteristic (risk variable) & $\begin{array}{l}\text { Baseline }(\mathrm{n}=1052) \\
\% \text { Enrollees }\end{array}$ \\
\hline Diabetes mellitus (self-report) & 15.5 \\
\hline Pre-diabetes & 17.7 \\
\hline $\mathrm{FBS} \geq 126 \mathrm{mg} / \mathrm{dl}$ & 8.7 \\
\hline Hypertension (self report) & 42.0 \\
\hline $\mathrm{SBP} \geq 140$ or $\mathrm{DBP} \geq 90, \mathrm{mmHg}$ & 33.8 \\
\hline $\mathrm{SBP} \geq 120$ or $\mathrm{DBP} \geq 80, \mathrm{mmHg}$ & 73.2 \\
\hline Pre-hypertensive (self-report) & 20.4 \\
\hline Prescribed medication for HBP (self-report) & 40.9 \\
\hline \multicolumn{2}{|l|}{ Hypercholesterolemia } \\
\hline $\mathrm{TC}>240 \mathrm{mg} / \mathrm{dl}$ & 5.8 \\
\hline $\mathrm{TC}>200 \mathrm{mg} / \mathrm{dl}$ & 25.3 \\
\hline \multicolumn{2}{|l|}{ Obesity } \\
\hline $\mathrm{BMI} \geq 30 \mathrm{~kg} / \mathrm{m}^{2}$ & 38.4 \\
\hline Mean BMI $\left(\mathrm{kg} / \mathrm{m}^{2}\right)$ & 32.2 \\
\hline \multicolumn{2}{|l|}{ Physical activity (self-report)_-days/week } \\
\hline$\leq 2$ days & 30.6 \\
\hline $3-4$ days & 24.7 \\
\hline$\geq 5$ days & 28.6 \\
\hline \multicolumn{2}{|l|}{ Smoking (self-report) } \\
\hline Everyday & 4.0 \\
\hline Some days & 1.5 \\
\hline $\begin{array}{l}\text { Family History (self-report; early onset } \\
\text { CVD in mother, sister, brother, or father) }\end{array}$ & 40.5 \\
\hline \multicolumn{2}{|l|}{ Heart disease (self-report) } \\
\hline $\mathrm{CHF}$ & 2.6 \\
\hline CAD & 3.0 \\
\hline Myocardial Infarction & 2.8 \\
\hline Angina & 3.8 \\
\hline Stroke (self report) & 2.5 \\
\hline
\end{tabular}

$H B P$ high blood pressure, $F B S$ fasting blood sugar, $S B P$ systolic blood pressure, $D B P$ diastolic blood pressure, $T C$ total cholesterol, $H D L$ high density lipoprotein cholesterol, $B M I$ body mass index, $C H F$ congestive heart failure, $C H D$ coronary heart disease, $C A D$ coronary artery disease, $C V D$ cardiovascular disease

Effect of the Intervention on Risk Factor Control

At baseline, there was substantial variation in the degree of control of each of the six major CVD risk factors: diabetes, hypertension, obesity, smoking, cholesterol, and physical activity (Fig. 3). At baseline, a greater percentage of participants had their diabetes, hypertension, and obesity controlled $(67 \%, 52 \%$, and $57 \%$, respectively), than smoking or cholesterol. As a result of the counseling intervention, and compared to baseline, there was a significant $(p<0.05) 10 \%$ increase in the percent of participants who attained improved control for hypertension (blood pressure $<140 / 90 \mathrm{mmHg}$ ). This improvement was not due to chance as statistical significance was confirmed following correction for multiple comparisons (Bonferroni). Interestingly, following the maintenance phase, the proportion of women who engaged regularly, preferably daily, in moderate physical activity for at least 30 minutes per day dropped by $7.4 \%(p<0.005$ following Bonferroni correction).

However, compared to baseline, there were no significant increases in control for any of the other risk factors by the end of counseling or the end of maintenance, although there were declines in the percentage of smokers and those with high cholesterol.

\section{Effect of the Intervention on Knowledge of CVD Risk Modification}

We evaluated the participant's knowledge of CVD risk factor modification strategies for hypertension, cholesterol, smoking, diabetes, physical activity, and obesity (Fig. 4). Baseline knowledge of CVD risk modification strategies was, overall, high for each risk factor. Knowledge of modification strategies was lowest for cholesterol and highest for obesity (53\% and 93\%, respectively). Compared to baseline, knowledge of effective CVD risk modification strategies for all CVD risk factors increased significantly $(p<0.05)$ following the counseling phase, except for obesity. The changes in knowledge that were attained at the end of counseling continued during the maintenance phase for hypertension and physical activity were maintained for the other risk factors and were unchanged from baseline for obesity.

Effect of the Intervention on Readiness for Cardiovascular Risk Behavior Change

The proportion of women who moved forward one or more stages of change for a given health behavior was assessed for diet, weight, physical activity, smoking, blood pressure, cholesterol, and diabetes. Compared to baseline, and corrected for multiple comparisons, there was a significant $(p<0.05)$ increase in forward movement in stage of change between baseline and end of counseling in the study participants (Fig. 5). The increase in forward movement for stage change varied from $+24 \%$ to $+37 \%$ for six of the risk factors (diet, weight management, physical activity, blood pressure, cholesterol, and diabetes). Although the increase in forward movement was the lowest $(10 \%$ increase) for smoking, the change was statistically significant compared to baseline. The forward movement in stage of change continued during the study maintenance phase and was significant compared to baseline for diet, physical activity, and diabetes, reached a plateau for weight and smoking, and significantly decreased during maintenance 


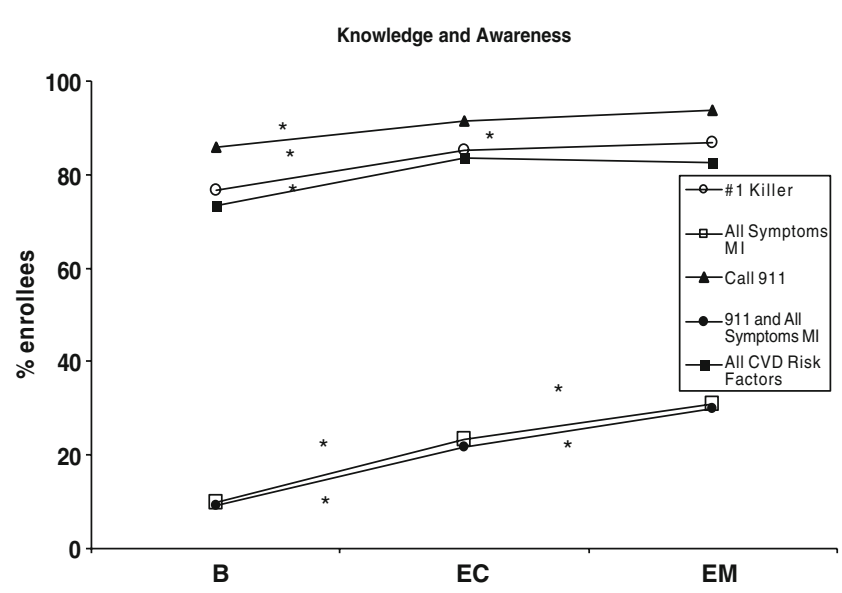

Fig. 2 Effects of the intervention on knowledge and awareness of heart disease for participants who completed all assessments. Cardiovascular outcomes (proportion of women) at baseline $(B)$, end of counseling $(E C)$, and end of maintenance $(E M)$ for women enrolled in the study. All comparisons are paired (pre- or post-intervention) for women with data at all three time points. Knowledge and awareness outcomes were assessed as follows: heart disease as the \#1 killer of women; all symptoms of a myocardial infarction (MI); calling 911; all symptoms of MI and calling 911; and all of the major cardiovascular disease (CVD) risk factors (diabetes, high blood pressure, high cholesterol obesity, physical inactivity, and smoking). Statistically significant changes $\left({ }^{*} p<0.05\right)$ for comparisons of B to EC and EC to EM are noted

for blood pressure and cholesterol. Compared to baseline, the greatest relative increase for stage change at each of the intervention time points occurred for physical activity with $37 \%$ and $39 \%$ of participants moving forward at least one stage of change by end of counseling and end of maintenance, respectively.

\section{Effect of the Intervention on Clinical Variables}

The effect of the community-based cardiovascular disease prevention intervention was assessed for a number of clinical parameters: weight, BMI, SBP, DBP, fasting total cholesterol, and fasting blood glucose (Fig. 6). At baseline, the mean weight and BMI of study participants was $189.3 \mathrm{lbs}$ and $32.1 \mathrm{~kg} / \mathrm{m}^{2}$, respectively. Therefore, this was an obese cohort. The mean systolic and diastolic blood pressure of study participants was 130.6 and $79.6 \mathrm{mmHg}$, respectively. Mean fasting total cholesterol and blood glucose were 190.2 and $101 \mathrm{mg} / \mathrm{dl}$, respectively. During the intervention, there was a small improvement in all clinical parameters, though the changes were not statistically significant following the counseling or maintenance phases, with one exception: compared to baseline, there was a significant $(p<0.05)$ reduction in systolic blood pressure to a mean systolic pressure of $127.9 \mathrm{mmHg}$ at the end of the maintenance phase.
Table 5 Participant follow-up for study outcomes

\begin{tabular}{|c|c|c|c|}
\hline & $\begin{array}{l}\text { Women with } \\
\text { follow-up }\end{array}$ & $\begin{array}{l}\text { Women } \\
\text { without } \\
\text { follow-up }\end{array}$ & $\begin{array}{l}\text { Missing at } \\
\text { follow-up } \\
(\%)\end{array}$ \\
\hline \multicolumn{4}{|l|}{ Knowledge and awareness } \\
\hline \#1 Killer & 423 & 614 & 59.2 \\
\hline All symptoms MI & 265 & 772 & 74.4 \\
\hline Call 911 & 395 & 642 & 61.9 \\
\hline $\begin{array}{l}911 \text { and all } \\
\text { symptoms MI }\end{array}$ & 241 & 796 & 76.8 \\
\hline All CVD risk factors & 332 & 705 & 68.0 \\
\hline \multicolumn{4}{|l|}{ Risk factor control } \\
\hline DM control & 396 & 641 & 61.8 \\
\hline HTN control $(<140 / 90)$ & 219 & 818 & 78.9 \\
\hline HTN control $(<120 / 80)$ & 219 & 818 & 78.9 \\
\hline Obesity control & 397 & 640 & 61.7 \\
\hline Physical activity & 461 & 576 & 55.5 \\
\hline Smoking control & 94 & 943 & 90.9 \\
\hline Cholesterol (>240) & 388 & 649 & 62.6 \\
\hline Cholesterol (>200) & 388 & 649 & 62.6 \\
\hline \multicolumn{4}{|l|}{ Risk factor knowledge } \\
\hline HTN & 386 & 651 & 62.8 \\
\hline $\mathrm{DM}$ & 419 & 618 & 59.6 \\
\hline Smoking & 356 & 681 & 65.7 \\
\hline Cholesterol & 416 & 621 & 59.9 \\
\hline Physical activity & 403 & 634 & 61.1 \\
\hline Obesity & 422 & 615 & 59.3 \\
\hline
\end{tabular}

\section{Discussion}

The goal of this study was to implement and evaluate outcomes for CVD risk knowledge and awareness, health state for clinical CVD risk factors, and behavior change in high-risk ethnic minority women during a total 7-month faith- and/or community-based CVD prevention intervention consisting of counseling and maintenance periods. Our results show that the program, delivered by both lay faithand community-based site leaders and health professionals, was overall very effective in achieving the proposed goals. Study participants made improvements in essentially every secondary outcome of the study, with over half of outcomes showing statistically significant gains compared to baseline. Although most of the gains were attained at the conclusion at the 4-month counseling phase, additional gains were realized in the subsequent 3-month maintenance phase.

In terms of the specific study outcomes, the program was very successful in increasing knowledge and awareness of all of the heart disease awareness outcomes and in increasing knowledge and awareness of successful cardiovascular risk factor modification interventions for nearly all of the cardiovascular risk factors. It was also very effective 


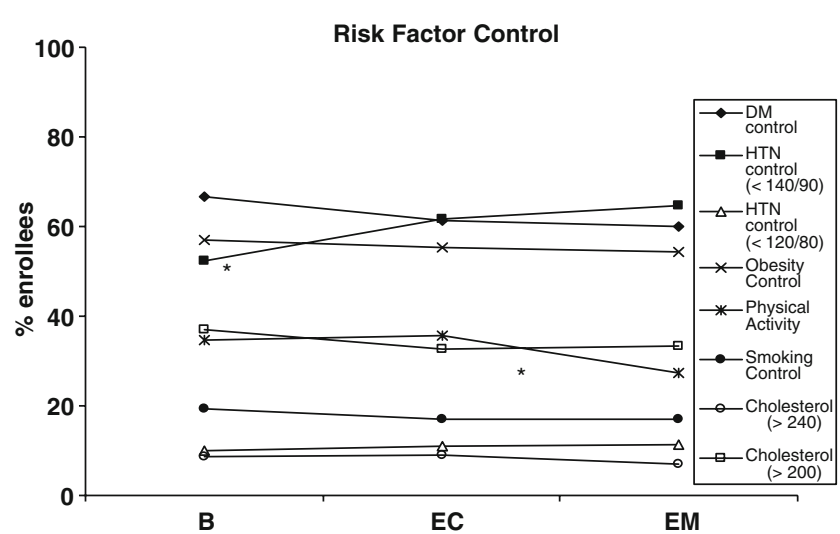

Fig. 3 Effects of the intervention on control of cardiovascular risk factors for participants who completed all assessments. Cardiovascular outcomes (proportion of women) at baseline $(B)$, end of counseling $(E C)$, and end of maintenance $(E M)$ for women enrolled in the study. All comparisons are paired (pre- or post-intervention) for women with data at all three time points. Control of cardiovascular risk factors were assessed for each of the following: diabetes (diabetics with fasting glucose $<=125 \mathrm{mg} / \mathrm{dl}$ ), hypertension (HTN; hypertensives with blood pressure $<140 / 90 \mathrm{mmHg}$; blood pressure $<120 / 80 \mathrm{mmHg}$ ), high total cholesterol (TC) $(\mathrm{TC}>240 \mathrm{mg} / \mathrm{dl}$ and $\mathrm{TC}>200 \mathrm{mg} / \mathrm{dl})$, obesity $\left(\mathrm{BMI}<30 \mathrm{~kg} / \mathrm{m}^{2}\right)$, physical activity (regular, preferably daily, moderate physical activity for at least $30 \mathrm{~min} /$ day), and smoking (current smokers). Statistically significant changes $\left({ }^{*} p<0.05\right)$ for comparisons of $\mathrm{B}$ to EC and EC to EM are noted

in helping participants move forward at least one stage of change for nearly all cardiovascular risk factors. In terms of risk factor control, the program was most successful in attaining control of systolic hypertension over a 7-month

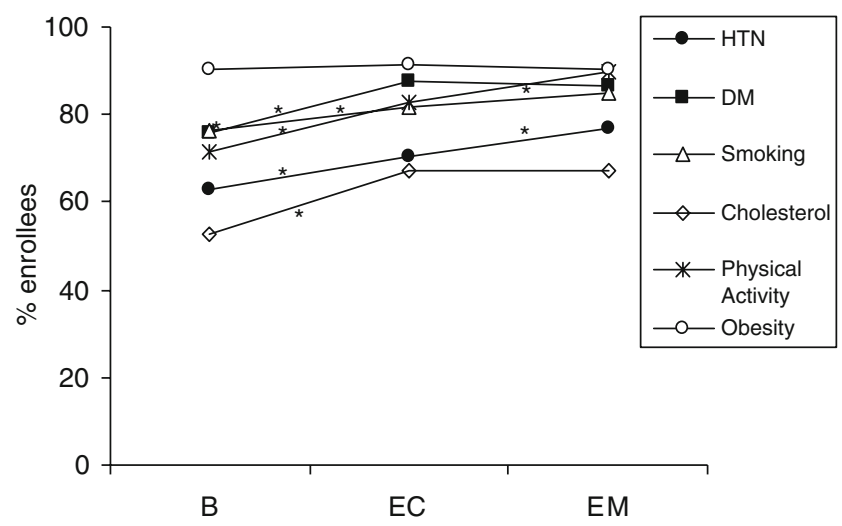

Fig. 4 Effects of the intervention on knowledge of cardiovascular risk modification for participants who completed all assessments. Cardiovascular outcomes (proportion of women) at baseline $(B)$, end of counseling $(E C)$, and end of maintenance $(E M)$ for women enrolled in the study. All comparisons are paired (pre- or post-intervention) for women with data at all three time points. Knowledge of effective cardiovascular risk modification interventions (e.g., utility of decreased sodium intake for blood pressure control, utility of decreased fat intake for control of high cholesterol, etc.) were assessed for each of the following risk factors: diabetes $(D M)$, hypertension $(H T N)$, high cholesterol, obesity, physical inactivity, and smoking. Statistically significant changes $\left({ }^{*} p<0.05\right)$ for comparisons of $\mathrm{B}$ to $\mathrm{EC}$ and $\mathrm{EC}$ to EM are noted

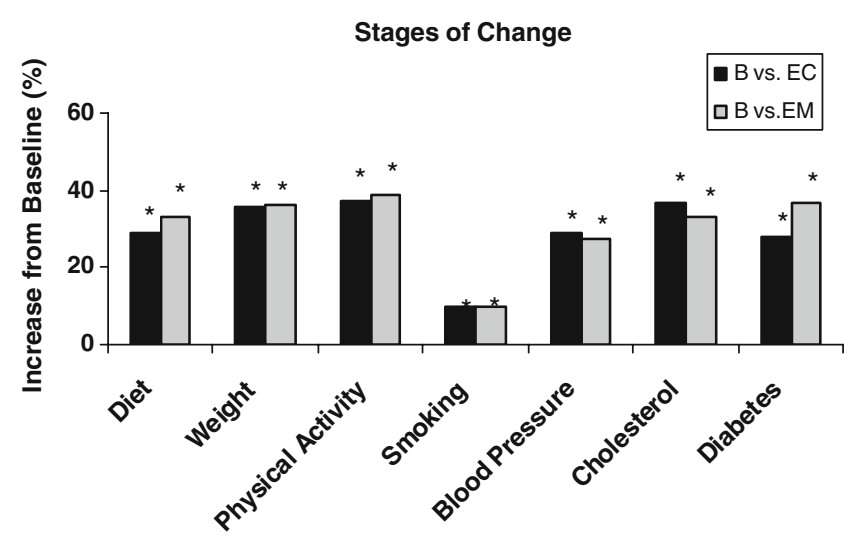

Fig. 5 Effects of the intervention on stages of change for cardiovascular risk factors for participants who completed all assessments. Proportion of women moving forward at least one stage of change (Prochaska's stages of change model, see text) for each cardiovascular risk factor (diet, weight, physical activity, smoking, blood pressure, cholesterol, and diabetes) at end of counseling $(E C)$ and end of maintenance $(E M)$ compared to baseline $(B)$ for women enrolled in the study. All comparisons are paired (pre- or post-intervention) for women with data at all three time points. Statistically significant changes $\left({ }^{*} p<0.05\right)$ for comparisons of $\mathrm{B}$ to $\mathrm{EC}$ and $\mathrm{EC}$ to $\mathrm{EM}$ are noted

intervention period. This may be a reflection of the fact that hypertension was the most prevalent cardiovascular risk factor in our study population (42\%). It may also be that blood pressure was affected by exercise and nutrition to a greater extent over the time period covered by this intervention. The lack of significant change in some of the other clinical parameters (e.g., cholesterol, fasting blood

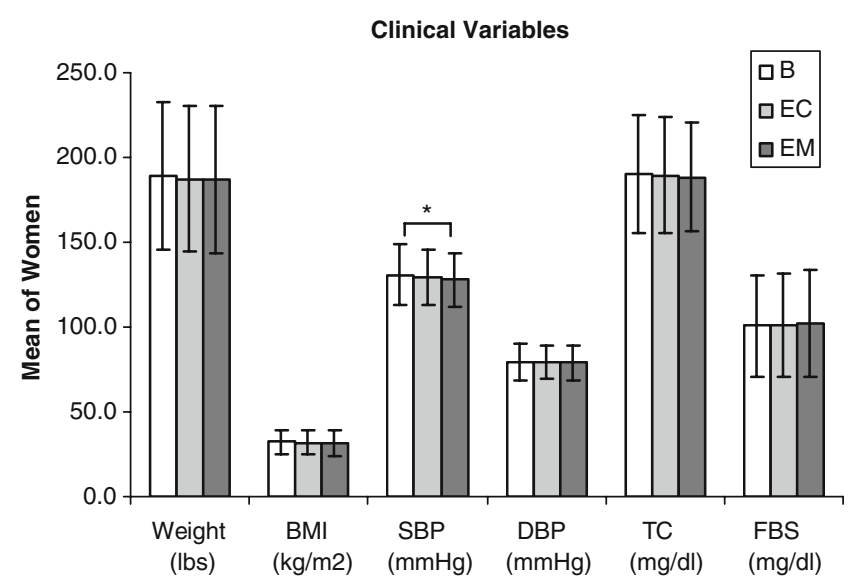

Fig. 6 Effects of the intervention on clinical parameters for participants who completed all assessments. Cardiovascular clinical outcomes at baseline $(B)$, end of counseling $(E C)$, and end of maintenance $(E M)$ for women enrolled in the study. All comparisons are paired (pre- or postintervention) for women with data at all three time points. Clinical parameters (means $\pm \mathrm{SEM}$ ) were assessed for the following: weight (lbs), body mass index $\left(B M I, \mathrm{~kg} / \mathrm{m}^{2}\right)$, diagnosis of diabetes (DM), systolic blood pressure $(S B P, \mathrm{mmHg})$, diastolic blood pressure $(D B P$, $\mathrm{mmHg}$ ), total cholesterol (TC, $\mathrm{mg} / \mathrm{dl})$, and fasting blood glucose ( $F B S$, $\mathrm{mg} / \mathrm{dl})$. Statistically significant changes $\left({ }^{*} p<0.05\right)$ for comparisons of B to $\mathrm{EC}$ and $\mathrm{EC}$ to $\mathrm{EM}$ are noted 
glucose) may, in part, have been due to the relatively large variation in values for these parameters in the study cohort.

The program was least successful in the primary outcomes of improving obesity and increasing physical activity in the study participants, though readiness to change increased significantly for these risk factors. The lack of effectiveness of the intervention in reducing obesity, and increasing physical activity, is in concert with the findings of many prior studies indicating that these two risk factors are not only difficult to modify but that behavior change may be related to a number of factors including stage of change, elapsed time in the action stages of change, effectiveness of motivational interviewing and behavior counseling techniques provided, use of self monitoring tools, information retention, and others [20, 29-36]. In addition, a longer period of community intervention and empowerment than provided here may be more effective for these two risk factors. In our study, it is interesting to note that participant's self assessment of their knowledge of successful obesity modification interventions did not increase. Perhaps the women felt that relative to other risk factors, there was greater presentation of new information for other risk factors. Regarding physical activity, the length of time and intensity of exercise increased by anecdotal reports from the participants, though frequency did not. Thus, future studies should look at not only frequency of exercise but also track time and intensity.

There were a number of limitations and challenges encountered and overcome during this study. They related primarily to participant retention, lead site coordinator time demands, and resources available. Although there was a relatively high dropout rate during the counseling phase $(32.3 \%)$, the dropout rate was subsequently relatively low for participants who remained in the program $(8.5 \%)$. In addition, overall, the program satisfaction was rated to be high by the study participants. Many of the women who participated and continued in the program did so out of their strong desire to be a part of a culturally relevant and supportive program. In addition, participation in the program provided participants with an opportunity to enhance their social network. The importance of social networks and social support structures in cardiovascular disease outcomes and cardiovascular risk behavior change has been previously reported $[37,38]$. This program placed higher than anticipated time demands on site leaders and coordinators who were responsible for program implementation. Preprogram site leader training sessions, efforts to provide a standardized curriculum across sites, and welldefined program goals were important elements to ensuring successful outcomes across sites. Regarding program resources, funds were limited and all sites relied heavily on local networks and partnerships for additional support and for providing meeting facilities for participants. Future interventions of this type should take into account these additional demands and provide funds and resources commensurate with the complexity of the type of faithand community-based health behavior intervention delivered and the rigor of the desired outcomes goals.

Although the CVD prevention program intervention was overall very effective in attaining program outcomes, there were a number of important "lessons learned." These are summarized as follows: (1) the program intervention implemented for this study required careful coordination between the program sponsor (DHHS-OWH), the lead sites, and the program implementation community- and/or faith-based sites. However, coordination and in-kind support was also required from partnering organizations and groups. It was, therefore, imperative that communication be seamless, and education reiterative, among all participating groups in order to ensure uniformity of implementation and a common understanding of the study goals and project outcomes. In addition, significant time and effort were required to build new collaborative community relationships, or adapt extant ones, with local partners, local community officials, and stakeholders in order to establish trust, ensure availability, build capacity, meet the needs of the program, and support program implementation. (2) The project's ambitious expectations to complete required program components within the limited timeframe was a major challenge. While adhering to program timelines, flexibility had to be built in to accommodate local and regional circumstances including summer months and vacations, weather, time commitment of site leaders, conflicting schedules of organizational partners, etc. (3) Utilizing the lead sites' and/or partnering organization's existing communication system to reach their constituents and members through organizational newsletters, flyers, emails, e-invites, letters, and church bulletins was an effective strategy for recruiting participants in the project. (4) Development of a standardized yet culturally appropriate, gender-specific health education curriculum, site leaders' guide, educational materials, and other culturally relevant materials and activities by each site were effective tools in generating small group discussions, subject participation in exercise sessions and program activities, and encouraged group cohesiveness and empowerment at each site. And (5) recruitment of site leaders who were peers to the study participants added to the effectiveness of the delivery of the curriculum and program because participants could better relate to them. Additionally, allowing the community- and faith-based groups to use their creativity and resources to develop maintenance sessions that focused on risk factors of cardiovascular disease was an effective strategy in participant retention and participation during this phase of the program. Additionally, this curricular flexibility afforded the community partners 
the opportunity to create sessions that were tailored to their community, have a sense of ownership over their sessions, and encouraged group cohesiveness.

In summary, our study and results demonstrate that a heart disease prevention educational intervention program aimed at high-risk women and delivered in communityand/or faith-based sites can be highly effective in improving CVD outcomes for women. Our findings have implications for the broader use of these strategies and approach in cardiovascular disease prevention for high-risk women. In order to further increase efficacy, future efforts should be directed towards health promotion programs among highrisk women, not only those with established cardiovascular disease and those more motivated to participate in clinical trials targeting lifestyle change. Given that the primary outcomes of reducing weight and increasing physical activity were not attained, studies should also address whether a health promotion approach is sufficient to attain improved outcomes in weight management and in increasing physical activity in this population. Future studies should not only assess the effect in lifestyle change and knowledge awareness but also address program duration, cost, and resources as a function of improved outcomes. It is possible that with a longer duration program and additional resources, even greater improvements in outcomes could have been observed, particularly for clinical targets. It would also be of benefit to follow a high-risk cohort of women for a longer duration to determine whether outcomes gains can be maintained and further optimized. Thus, policy makers and funding agencies should consider faith-based and community intervention programs of this type in their priority initiatives. In addition, because of the success of the intervention delivered, it would be of interest to determine whether more complex risk factor patterns and new and emerging CVD risk factors, such as the metabolic syndrome, inflammatory markers, and subclinical disease markers, can be similarly and favorably modified.

In conclusion, we observed that when working with faith-based national and civic organizations targeting highrisk women of color, it is beneficial to align efforts with both the national faith-based and/or the local community organization to ensure that program implementation efforts are effective and successful. CVD interventions for women of color should be designed to enhance the strengths of community resources inclusive of community stakeholders and members of the target population during planning and implementation and identify race, culture, and gender as contributing factors to CVD. The interventions should also incorporate program components that encourage healthy social networks and empowerment. These strategies will help to ensure that high-risk women and those from underrepresented groups will derive a greater sense of accountability and self-worth from a program designed for and by them. These are important tools in the fight against heart disease - the leading killer for all women.

Acknowledgements This work was supported by a cooperative agreement award from the office on Women's Health in the United States Department of Health and Human Services (DHHS/OWH), the Office of Research on Women's Health at the National Institutes of Health (NIH/ORWH), and the Francis Lazda Endowment in Women's Cardiovascular Medicine to AV. This publication was also made possible by Grant Number UL1 RR024146 to the UC Davis Clinical and Translational Science Center from the National Center for Research Resources (NCRR), a component of the National Institutes of Health (NIH), and NIH Roadmap for Medical Research.

Open Access This article is distributed under the terms of the Creative Commons Attribution Noncommercial License which permits any noncommercial use, distribution, and reproduction in any medium, provided the original author(s) and source are credited.

\section{Appendix}

The authors would also like to acknowledge the coordinating DHHS-OWH program officer, Susan Russell, MA and the following contributing investigators, research staff at each lead site, data coordinating staff, national organizations and their leaders working in partnership with their members and constituents, and others as detailed below. The benefits and positive impact of the program activities within the communities served are the direct result of the efforts of these organizations as follows:

$A B C$ : Rosalyn Scott, M.D., MSHA: principal investigator; Ann L. Taylor, M.D.: program clinical director; Akilah Heggs, MA: senior director, Community Programs; Jacqueline Lewis: program manager; Becky E. Leach: program coordinator and elder, United Churches of Jesus Christ; Carol Hall: data analyst.

The Imperative: Cheryl S. Taylor, $\mathrm{PhD}, \mathrm{MSN}, \mathrm{RN}-$ principal investigator; Shavon Arline, MPH - co-investigator/project director; Judith May, BS-program assistant; Camonia Long, MS - research assistant; Eleanor Hinton Hoytt - president and CEO; Valerie Rochester-director of programs. Partner sites: African Methodist Episcopal Church Health Commission, Dr. Miriam Burnett-medical director; Center for Black Women's Wellness, Jemea Dorsey-executive director; Mocha Moms Incorporated, Donna "Dee-Dee" Jackson_national president; Zeta Phi Beta Sorority Incorporated, Barbara Moore-international president; and Zeta Phi Beta Sorority, Incorporated, Dr. Constance Hendricks - director of national Zetas Helping Other People Excel.

RCSHD: Shannon S. Carrow, MS, Executive Director, Research Center for Stroke \& Heart Disease, The Jacobs Neurological Institute, State University of New York at Buffalo: Primary Investigator; Kristen E. Martin, BA, Project Manager Research Center for Stroke \& Heart 
Disease, The Jacobs Neurological Institute, State University of New York at Buffalo: Co-Investigator. Sekar Raju, PhD, Assistant Professor of Marketing, Iowa State University: Data Analyst. Research Center for Stroke \& Heart Disease, The Jacobs Neurological Institute Staff: Shannon S. Carrow, MS, Executive Director; Kristen E. Martin, Project Manager; Jerry Irons, Data Manager/Computer Programmer; Barbara Crocker, Research Assistant; Taywanda Bolden, Research Assistant. Multidisciplinary Planning Committee (MPC), H.E.R. Faith Fellowship: Monica Baskin, PhD, Assistant Professor, Department of Health Behavior, School of Public Health, University of Alabama at Birmingham; Kathryn P. Derose, MPH, PhD, Health Policy Researcher, Rand Health; Maryetta DuBois, RN, Parish Nurse, Evangelistic Temple \& Community Church, Buffalo, New York; Rev. Barbara J. Evans, MPH, RNC, ANP, Minister of Health \& Wholeness, Grace Baptist Church, Mt. Vernon, New York; Thomas Lasater, PhD, Professor, Department of Community Health; Director, Institute for Community Health Promotion, Brown Medical School; Frederick E. Munschauer III, MD, Chief, Jacobs Neurological Institute; Smith Professor and Chair, Department of Neurology, School of Medicine and Biomedical Sciences, State University of New York at Buffalo; Thomas Pearson, MD, MPH, PhD, Albert D. Kaiser Professor, Community and Preventative Medicine, Senior Associate Dean for Clinical Research, University of Rochester. Advisors, H.E.R. Faith Fellowship: Mimi Kiser, RN, MPH, CHES, Associate Director, Interfaith Health Program Rollins School of Public Health, Emory University; Diane Becker, RN, ScD, MPH, Director of the Center for Health Promotion, Professor of Medicine \& Public Health Policy and Management, Johns Hopkins University. Faith Sites, $H$. E.R. Faith Fellowship: Atlanta Intercultural Ministries, Inc: Faith Site Leader (FSL) Jean M. Murphy, RN; Faith Site Leader Assistant (FSLA): Gloria G. Gonzalez. Brown Chapel AME Church: FSL: Rev. Maymette E. Dolberry; FSLAs: Ruby J. Burns and Lisa Lewis; Pastor: Jerry Hatter. Centennial Christian Church: FSL: Iva J. Barfield-Lambert, RN; FSLA: Connie Wilson. Grace Church Episcopal: FSL: Barbara A. Mountjoy, RN; Pastor: The Rev. Steven C. Wilson. Most Holy Redeemer Church: FSL: Amalia L. McIntyre, RN; FSLA: Emma E. Velasquez, RN; Pastor: Monsignor Donald F. Hanchon. La Sagrada Familia: FSL: Quilma V. Hueter, RN; FSLA: Gayle Donahue, RN; Pastor: Rev. David Fallon. Mt. Olive Baptist Church: FSL: Donna J. Chapman; FSLA: Judy C. Starks, PCA; Pastor: Rev. William Gillison. Our Lady of Loretto Church: FSL: Donna M. Wald, RN; FSLA: Linda J. Small; Pastor: Fr. Jim P. Antoine. Saint Andrew Kim Catholic Church: FSL: Mo Kyung-Sin, DSN, RN; FSLA: Veronica S.M. Kim; Pastor: Jun-Sup Jung.
University of California, Davis: Investigator Team: Amparo C. Villablanca, MD Professor Cardiovascular Medicine and Director, Women's Cardiovascular Medicine Program and Associate Director Women's Center for Health; Kimberly Jeffries Leonard, PhD, Co-Investigator, The Links, Inc.; Seleda Williams, MD, MPH, Collaborating Investigator and Public Health Medical Officer, California Department of Health Services; Dianne Hyson, PhD, MS, RD Collaborating Investigator and Assistant Professor and Director of the Didactic Program in Dietetics at California State University Sacramento; Liana Lianov, MD, MPH, Collaborating Investigator and Medical Officer MediCal Managed Care, California Department of Health Services; Barbara Ross, BA, Director, Government and Community Relations, UC Davis. The Links Inc.: Kimberly Jeffries Leonard, PhD, Co-Investigator and Director, National Trends and Services; Sandra Malone, Western Area Director. University of California, Davis data team and staff: Maureen Calpo, Administrative Assistant; Christina Slee, Research Assistant and Data Analyst; Cris Warford, Research Assistant; Hassan Baxi, Data Manager/Computer Programmer; Kent Anderson, Database Architect; Susan Long, Research Coordinator. Site Leaders and Co-Site Leaders, The Links, Inc: Veronica Henry, Eastern Shore, NY; Mae Johnson, Mae Rogers, Dorothy Toney, Fresno, CA; Annye Nichols, Ann Wade, Phoenix, AZ; Beverly Anderson, Prince Georges County, MD; Barbara Smith-Nash, Delores Covington, Sacramento, CA; Earlene Threatt Larkin, Nancy Sewell, Selma, AL; Marcia Bowden, Bridget Chisholm, Shelby County, TN; Alana Broady, Windy City, IL.

\section{References}

1. American Heart Association. (2005). Heart Disease and Stroke Statistics-2005 Update. Dallas: American Heart Association.

2. American Heart Association. (2005). Women and Cardiovascular Diseases-Statistics. Dallas: American Heart Association.

3. Grady, D., Chaput, L., \& Kristof, M. (2003). Results of systematic review of research on diagnosis and treatment of coronary heart disease in women. Evidence Report/Technology Assessment (Summary), accessed at (http://www.ahrq.gov/clinic/tp/chdwomtp.htm).

4. Practice News. (2003). Red dress attracts new attention to heart disease in women. Cardiology, 32, 1-4.

5. Mosca, L., Ferris, A., Fabunmi, R., \& Robertson, R. M. (2004). Tracking women's awareness of heart disease: an American Heart Association national study. Circulation, 109, 573-579.

6. McSweeney, J. C., Cody, M., \& Crane, P. B. (2001). Do you know them when you see them? Women's prodromal and acute symptoms of myocardial infarction. Journal of Cardiovascular Nursing, 15, 26-38.

7. NIH. (2001). Women's Heart Health: Developing a National Health Education Action Plan. Bethesda: National Heart, Lung and Blood Institute. Strategy Development Workshop Report, National Institutes of Health. 
8. Patel, H., Rosengren, A., \& Ekman, I. (2004). Symptoms in acute coronary syndromes: does sex make a difference? American Heart Journal, 148, 27-33.

9. Gallagher, R., McKinley, S., \& Dracup, K. (2003). Predictors of women's attendance at cardiac rehabilitation programs. Progress in Cardiovascular Nursing, 18, 121-126.

10. Thompson, T. G., Gerberding, J., \& Sondik, E. (2004). Health, United States, 2004. Hyattsville: NCHS. with Chartbook on Trends in the Health of Americans.

11. American Indians/Alaska Natives and Cardiovascular Diseases. (2005). Statistics. Dallas, Texas: American Heart Association.

12. Association, A. H. (2005). Hispanics/Latinos and cardiovascular diseases-statistics. Dallas: Association AH.

13. Anonymous (1998). Missed opportunities in preventive counseling for cardiovascular disease: United States. Morbidity and Mortality Weekly Report, 47, 91-95.

14. Ferris, A., Robertson, R. M., Fabunmi, R., \& Mosca, L. (2005). American Heart Association and American Stroke Association national survey of stroke risk awareness among women. Circulation, 111, 1321-1326.

15. Krummel, D. A., Koffman, D. M., Bronner, Y., Davis, J., Greenlund, K., Tessaro, I., et al. (2001). Cardiovascular health interventions in women: What works? $J$ Womens Health Gend Based Med, 10, 117-136.

16. Lasco, R. A., Curry, R. H., Dickson, V. J., Powers, J., Menes, S., \& Merritt, R. K. (1989). Participation rates, weight loss, and blood pressure changes among obese women in a nutrition-exercise program. Public Health Reports, 104, 640-646.

17. Yanek, L. R., Becker, D. M., Moy, T. F., Gittelsohn, J., \& Koffman, D. M. (2001). Project Joy: Faith Based Cardiovascular Health Promotion for African American Woment. Public Health Rep, 116(1), 68-81.

18. Burke, L. E., Dunbar-Jacob, J. M., \& Hill, M. N. (1997). Compliance with cardiovascular disease prevention strategies: a review of the research. Ann Behav Med, 19, 239-263.

19. Farquhar, J. W., Fortmann, S. P., Flora, J. A., Taylor, C. B., Haskell, W. L., Williams, P. T., et al. (1990). Effects of communitywide education on cardiovascular disease risk factors. The Stanford Five-City Project. Jama, 264, 359-365.

20. Frank, L. L., Sorensen, B. E., Yasui, Y., Tworoger, S. S., Schwartz, R. S., Ulrich, C. M., et al. (2005). Effects of exercise on metabolic risk variables in overweight postmenopausal women: a randomized clinical trial. Obesity Research, 13, 615-625.

21. Lefebvre, R. C., Lasater, T. M., Carleton, R. A., \& Peterson, G. (1987). Theory and delivery of health programming in the community: the Pawtucket Heart Health Program. Preventive Medicine, 16, 80-95.

22. Madsen, J., Sallis, J. F., Rupp, J. W., Senn, K. L., Patterson, T. L., Atkins, C. J., et al. (1993). Process variables as predictors of risk factor changes in a family health behavior change program. Health Education Research, 8, 193-204.

23. Prochaska, J. O., DiClemente, C. C., \& Norcross, J. C. (1992). In search of how people change. Applications to addictive behaviors. American Psychologist, 47, 1102-1114.

24. van der Bij, A. K., Laurant, M. G., \& Wensing, M. (2002). Effectiveness of physical activity interventions for older adults: a review. American Journal of Preventive Medicine, $22,120-133$

25. Young, D. R., Gittelsohn, J., Charleston, J., Felix-Aaron, K., \& Appel, L. J. (2001). Motivations for exercise and weight loss among African-American women: focus group results and their contribution towards program development. Ethnicity and Health, 6, 227-245.

26. Wallerstein, N. (2006). What is the evidence on effetiveness of empowerment to Improve Health? Health Evidence Network: 6.

27. Berkman, L. F., \& Glass, T. (2006). Social Integration, Social Networks, Social Support, and Health. In L. F. Berkman \& I. Kawachi (Eds.), Social Epidemiology (pp 137-173). New York: Oxford University Press.

28. Taylor, C. (2007). Reaching African American Women in New Orleans Louisiana. DHHS Center for Disease Control. http:// www.cdc.gov/reach/pdf/LA_New_Orleans.pdf

29. Sorenson, M. (1997). Maintenance of exercise behavior for individuals at risk for cardiovascular disease. Perceptual and Motor Skills, 85, 867-880.

30. Al-Ali, N., \& Haddad, L. G. (2004). The effect of the health belief model in explaining exercise participation among Jordanian myocardial infarction patients. Journal of Transcultural Nursing, $15,114-121$

31. Logue, E. E., Jarjoura, D. G., Sutton, K. S., Smucker, W. D., Baughman, K. R., \& Capers, C. F. (2004). Longitudinal relationship between elapsed time in the action stages of change and weight loss. Obesity Research, 12, 1499-1508.

32. Smith, D. E., Heckemeyer, C. M., Kratt, P. P., \& Mason, D. A. (1997). Motivational interviewing to improve adherence to a behavioral weight-control program for older obese women with NIDDM. A Pilot Study. Diabetes Care, 20, 52-54.

33. Steptoe, A., Kerry, S., Rink, E., \& Hilton, S. (2001). the impact of behavioral counseling on stage of change in fat intake, physical activity, and cigarette smoing in adults at increased risk of coronary heart disease. American Journal of Public Health, 91, $265-269$.

34. Jeffery, R. W., French, S. A., \& Rothman, A. J. (1999). Stage of change as a predictor of success in weight control in adult women. Health Psychology, 18, 543-546.

35. Goldberg, J. H., \& Kiernan, M. (2005). Innovative techniques to address retention in a behavioral weight-loss trial. Health Education Research, 20, 439-447.

36. Tinker, L. F., Patterson, R. E., Kristal, A. R., Bowen, D. J., Kuniyuki, A., Henry, H., et al. (2001). Measurement characteristics of 2 different self-monitoring tools used in a dietary intervention study. ournal of the American Dietetic Association, 101, 1031-1040.

37. Pearson, T. A. (1987). Multiple risk factors for coronary artery disease: behavioral factors in preventive cardiology. American Journal of Cardiology, 60, 74J-79J.

38. Rutledge, T., Reis, S. E., Olson, M., Owens, J., Kelsey, S. F., Pepine, C. J., et al. (2004). Social networks are associated with lower mortality rates among women with suspected coronary disease: the National Heart, Lung, and Blood Institute-Sponsored Women's Ischemia Syndrome Evaluation study. Psychosomatic Medicine, 66, 882-888. 